\title{
Sellar Neuroblastoma
}

National Cancer Institute

\section{Source}

National Cancer Institute. Sellar Neuroblastoma. NCI Thesaurus. Code C155772.

A rare neuroblastoma arising from the sella turcica. 